\title{
Determination of Soft Tissue Cephalometric Norms of Rajasthan Population Using Holdway Analysis
}

\author{
Bhavik Patel ${ }^{1}$, Koshalraj Goyal $^{2}$ \\ ${ }^{l}$ Department of Orthodontics And Dentofacial Orthopaedics, Siddhpur Dental College And Hospital, India \\ ${ }^{2}$ Department of Oral And Maxillofacial Surgery, Siddhpur Dental College And Hospital, India
}

\begin{abstract}
:
Introduction: Different regional groups have different soft tissue structures, so it is necessary to establish the soft tissue norms of different regional groups for effective orthodontic treatment.

Materials and methods: 270 lateral cephalograms of subjects with age group 18-25 years, Angle's class I dentoalveolar malocclusion, normal overjet and overbite, presence of all permanent teeth and well balanced facial profile were selected. Holdway soft tissue cephalometric analysis was performed and studied.

Result: The H-angle, upper and lower lip to $S$ - line, upper lip curvature, lower lip to H line, upper and lower sulcus depth and upper lip strain factor were higher whereas nasolabial angle, upper lip to E-line and nose tip to $H$ line were lesser for Rajasthan population as compared to Caucasians.

Conclusion: Rajasthanis have protrusive upper and lower lips as compared to Caucasians.

Keywords: Caucasians, E-line, H-angle, Lateral cephalogram, Rajasthanis
\end{abstract}

\section{Introduction}

Dr. Angle ${ }^{1}$ interpreted the concept of balance - again a normality standard - as follows: "There is a law for determining the best balance of features, or at least the best balance of the mouth with the rest of the features. It is that the best balance, the best harmony, the best proportion of the mouth in its relations to the other features require that there shall be the full complement of the teeth and that each tooth shall be made to occupy its normal position -- normal occlusion."

For many years, research workers have traced, measured and compared dozens of planes, angles and dimensions on head radiographs. From these observations, a concept gradually evolved of what constitutes acceptable balance and harmony of the component parts of the face. Dentofacial balance and harmony and growth and development have been studied by many investigators: namely height, breadth, depth and timing; using lateral and antero-posterior radiographs ${ }^{2}$.

According to Sarkar ${ }^{3}$, Indians are predominantly dolichocephalic, however, mesocephals and brachycephals are found in appreciable numbers. The research of the last two decades of Cotton, Takanon, Wong, Haralabakis, Altemus and Kotak ${ }^{4}$ had indicated that the normal measurements of one group can't be considered normal for other racial groups. The cephalometric parameters of soft tissue of one population can't be applied to another group. So, it becomes necessary to understand the soft tissue cephalometric norms for different groups of population. Thus, the present study was conducted to determine the soft tissue cephalometric norms for Rajasthan.

\section{Materials And Methods}

The study was conducted in the Department of Orthodontics and Dentofacial Orthopaedics, Darshan dental college and hospital, Loyara, Udaipur (Rajasthan). The sample was collected from out patient department of the hospital.

\section{Source Of The Data}

The present analysis was made on lateral cephalograms of 270 subjects with well balanced and acceptable facial profile of Rajasthan population.

\section{Methods Of Collection Of Data}

Subjects with age group of 18-25 years having class I dento-alveolar malocclusion, good facial symmetry, presence of all permanent teeth, normal overjet and overbite and acceptable facial profile were selected by three trained orthodontists, who belonged to the department of Orthodontics and Dentofacial Orthopaedics, Darshan Dental College. 


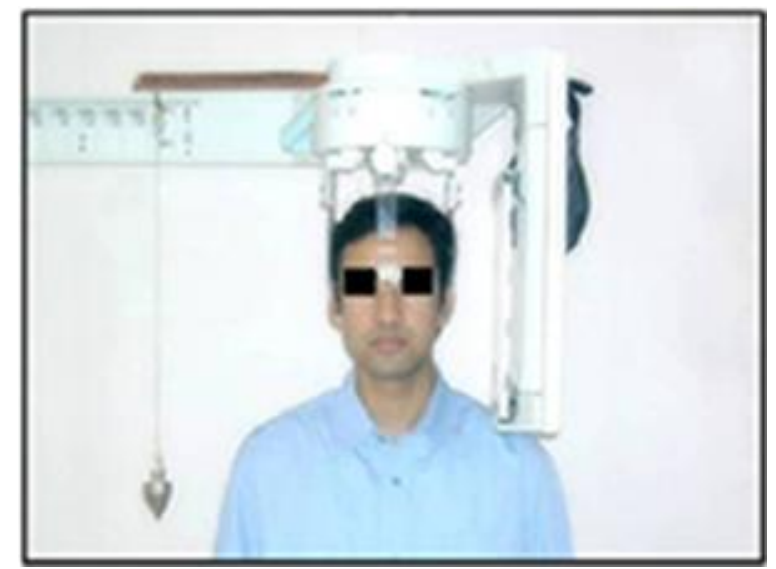

(Fig: 1- A patient with natural head position)

(Fig:1) The radiographic apparatus used was Orthoralix 9200 cephalometer. The Kodak x-ray films of 8 " x 10 " were used. All lateral cephalometric radiographs were taken in centric occlusion with lips in repose and the Frankfort horizontal plane oriented horizontally according to natural head position. The True Vertical Line was made by a thin steel chain hanging from the $\mathrm{X}$-ray machine.

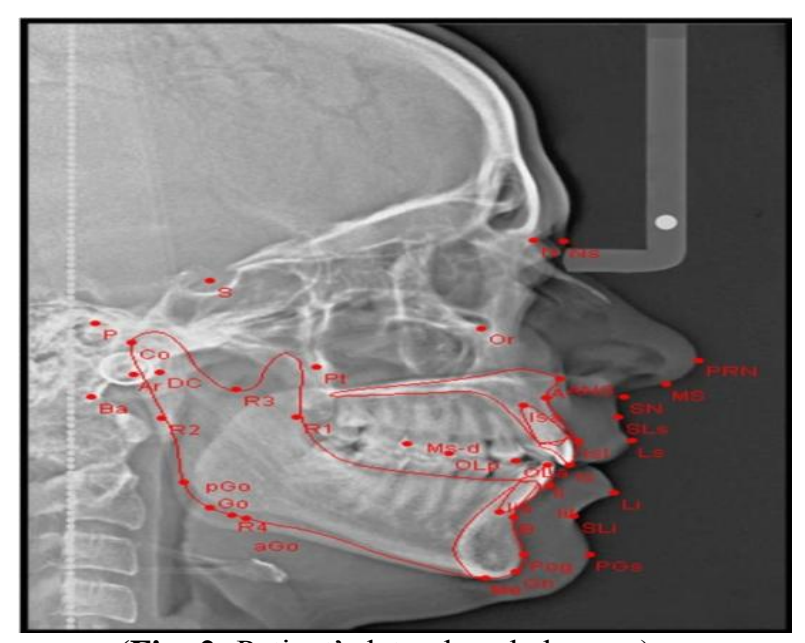

(Fig: 2- Patient's lateral cephalogram)

Foot Notes: S-Sella turcica, P- Porion, N-Nasion, Or- Orbitale, Co- Condylion, PRN- Pronasale, ANSAnterior nasal spine, SN- Subnasale, Ba- Basion, Pog- Pogonion, PGs- Soft tissue pogonion, A- Point A, BPoint B, Gn- Gnathion, Me- Menton, SLs-Sulcus labial superior, Ls- Labial superior (upper lip), SLi- Sulcus labial inferior, Li- Labial inferior (lower lip), Is- Incisor superior (Upper incisor tip), Ii- Incisor inferior (Lower incisor tip), Isa- Incisor superior apex (Upper incisor root), Iia- Incisor inferior apex (Lower incisor root)

(Fig:2) To determine the magnification error, $1 \mathrm{~cm}$ diameter of stainless steel ball was placed on the nose positioner on the X-ray machine. Total 300 lateral cephalograms were taken. Out of 300 lateral cephalograms, 30 lateral cephalograms (17 males, 13 female) were excluded because cephalometrically, they indicated skeletal class II or class III pattern. Holdway soft tissue analysis was performed.

\section{Results}

To check the operator's reliability and reproducibility, 10 males and 10 females lateral cephalograms were randomly selected and retraced after the gap of one week. Statistically, there was no significant difference found in mean, standard of deviation and 'p' value. It indicated that there was no significant intra-examiner variability found.

There was significant difference was found in mean values of soft tissue factors such as $\mathrm{H}$ - angle, nasolabial angle and in linear measurements like upper lip to $S$ - line, lower lip to $S$ - line, upper lip curvature, lower lip to $\mathrm{H}$ line, upper and lower sulcus depth, upper lip strain factor, upper lip to E-line and nose tip to $\mathrm{H}$ line in Rajasthan and Caucasian population which were represented in Table. 
Table: of results Comparison of Rajasthanis and Caucasians -- Soft tissue factors

\begin{tabular}{|c|c|c|c|c|c|c|}
\hline \multirow{2}{*}{ e } & \multirow{2}{*}{ Parameter } & \multicolumn{2}{|c|}{ Rajasthanis } & \multicolumn{2}{|c|}{ Caucasians } & \multirow{2}{*}{$\begin{array}{l}\text { 'P' } \\
\text { Value }\end{array}$} \\
\hline & & Mean & Sd & Mean & Sd & \\
\hline 1 & $\begin{array}{l}\text { Upper Lip To E-Line } \\
(\mathrm{Mm})\end{array}$ & -2.54 & 2.5 & 0 & & $<0.05$ \\
\hline 2 & Upper Lip To S-Line (Mm) & 0.81 & 1.866 & 0 & & $<0.01$ \\
\hline 3 & $\begin{array}{l}\text { Lower Lip To S- Line } \\
(\mathrm{Mm})\end{array}$ & 1.9 & 2.51 & 0 & & $<0.01$ \\
\hline 4 & H-Angle & 14.5 & 3.24 & 11 & & $<0.01$ \\
\hline 5 & Nasolabial Angle & 98.2 & 9.43 & 102 & 8 & $<0.01$ \\
\hline 6 & Upper Lip Curvature (Mm) & 4.38 & 1.39 & 3.5 & & $<0.01$ \\
\hline 7 & Nose Tip To H-Line (Mm) & 7.87 & 3.23 & 12 & & $<0.01$ \\
\hline 8 & $\begin{array}{l}\text { Lower Lip To H-Line } \\
(\mathrm{Mm})\end{array}$ & 1.93 & 1.63 & 0 & & $<0.01$ \\
\hline 9 & Upper Sulcus Depth (Mm) & 7.08 & 2.26 & 5 & & $<0.01$ \\
\hline 10 & Lower Sulcus Depth (Mm) & 5.7 & 1.59 & 5 & & $<0.01$ \\
\hline 11 & $\begin{array}{l}\text { Upper Lip Strain Factor } \\
(\mathrm{Mm})\end{array}$ & 1.4 & 1.98 & 1 & & $<0.05$ \\
\hline
\end{tabular}

Table footnotes for soft tissue factors: E-line - Rickett's line, S- line- Steiner's line

\section{Discussion}

The goal of Orthodontics is to achieve optimal facial attractiveness. For this, the Orthodontist has to assess not only hard tissue but also soft tissue of the face. The old school of thought that the soft tissue curtain will also alter in accordance to the skeletal and dental changes, had long been questioned. This led to culmination of newer concept which lay emphasis upon harmonizing facial profile too, as it undergoes alterations as a result of orthodontic treatment. Thus, the traditional cephalometric concepts based on hard tissue analyses exclusively are gradually being supplemented with soft tissue analysis ${ }^{3}$.

There was statistically significant increase in $\mathrm{H}$-angle and decrease in nasolabial angle in Rajasthanis than Caucasians. This is in agreement with the study done by Lew KK et al., $(1992)^{5}$ on Chinese adults and Manish Valiathan et al., (1999) ${ }^{6}$ on North and South Indians, but is in contrast to the study done on IndoAryans $^{3}$, who showed H-angle is within the normal range and also in contrast to study done by Helio Scavone $e t$ al., $(2007)^{7}$ on White Brazilian adults, who showed obtuse nasolabial angle when compared to Caucasians. The increased $\mathrm{H}$-angle in Rajasthanis indicates protrusive upper lips, which was also supported by the findings like increase in the distance from upper and lower lips to S-line and decrease in the distance from nose tip to H-line; even though, the linear measurement of E-line to upper lip showed retrusive upper lip which was of statistically low significant.

There was also increase in parameters like upper lip curvature, lower lip to H-line, upper sulcus depth, lower sulcus depth, upper lip strain factor in Rajasthanis as compared to Caucasians. The reason behind this might be the proclined upper incisors and increased H- angle in Rajasthanis. Binu Purushothaman et al., $(2012)^{8}$ showed that there was increase in upper lip curvature, $\mathrm{H}$-angle, upper sulcus depth and lower lip to $\mathrm{H}$-line but decrease in nasolabial angle in Rajasthanis than Malabar population in Northern Kerala. This indicated that upper lip is more prominent in Rajathan population than Malbar population.

\section{Summary And Conclusion}

Current requirements of presentability and demand on good impressive appearance make it mandatory to study the pattern of ethnic groups. An attempt was made to establish the cephalometric norms of Rajasthan population by studying the soft tissue features.

\section{The findings can be summarized as follows}

- Rajasthanis had increased upper lip thickness, protrusive upper and lower lips, increase upper and lower sulcus depth as compared to Caucasians.

\section{References}

[1]. Alfred T. Baum, A cephalometric evaluation of the normal skeletal and dental pattern of children with excellent occlusion. Angle Orthod 1951;21(2): 96-103

[2]. William B. Downs, Analysis of the dentofacial profile. Angle Orthod 1956; 26(4): 191-212

[3]. Harpreet Grewal, S.S. Sidhu and O.P. Kharbanda, Cephalometric appraisal of the craniofacial pattern in Indo-Aryans. J. of Ind. Orthod 1995; 26(2): 43-48 
[4]. Ravindra Nanda and Ram S. Nanda, Cephalometric study of the dentofacial complex of North Indians. Angle Orthod 1969; 39(1): $22-28$

[5]. Lew KK, Ho KK and Kens SB, Soft -tissue cephalometric norms in Chinese adults with esthetic facial profiles. J. of Oral Maxillofacial Surgery 1992; 50(11): 84-90

[6]. Manish Valiathan, Ashima Valiathan and Suresh, A comparison of cephalometric norms of North and South Indians using Powell and Holdway analyses. J. of Indi. Orthod 1999; (32): 122-126

[7]. Helio Scavone Jr, Wesley Zahn Silva, Karyana Martins do Valle-Corotti and Ana Carla Raphaelli Nahas, Soft tissue profile in White Brazilian adults with normal occlusion and well balanced faces. Angle Orthod 2007; 78(1): 58-63

[8]. Binu Purushothaman, Ranjith Raveendran Shobha Sundareswaran and M Harindranathan, Soft tissue cephalometric norms of Malbar population in Northern Kerala: An epidemiologic study. J. of Indi. Orthod 2012; 32(2): 65-69 